\title{
APROXIMACIÓN A LA ORGANIZACIÓN SEMÁNTICA DEL LÉXICO SOBRE JUEGOS Y DIVERSIONES
}

\author{
Antonio Manjón-Cabeza Cruz \\ Universidad de Granada \\ amanjoncabeza@ugr.es
}

\section{Resumen}

En los últimos años estamos asistiendo a la inclusión de consideraciones psicolingüísticas en los ya numerosos trabajos sobre léxico disponible. Entre esas consideraciones, una de las más interesantes -ya que puede tener rendimientos descriptivos, teóricos y de planificación de la enseñanza- consiste en el establecimiento de redes semánticas partiendo de los corpus primarios que nos proporcionan las encuestas léxicas. En este trabajo presento la metodología y los resultados obtenidos para el campo semántico de "Juegos y diversiones" tomando como base las encuestas de 142 individuos de la provincia de Toledo con diferentes características psicosociales. Los resultados indican la organización en dos conglomerados principales -deportes y juegos de mesa-y otros secundarios como juegos escolares y entretenimientos audiovisuales. Estas apreciaciones han de ser matizadas si atendemos a las características psicosociales de los sujetos. En este caso es significativa la variación de las redes semánticas según el factor edad y el factor sexo.

PALABRAS CLAVE: redes semánticas, juegos, psicolingüística, disponibilidad léxica.

\begin{abstract}
In the last years we are seeing the inclusion of psycholinguistic considerations in the works on lexical availability. One of the most interesting of these considerations -because it may have descriptive, theoretical and educational planning meanings- is the creation of semantic networks that are based in the primary corpus given us by lexical surveys. This work presents the methodology and results for the semantic field of "Games and amusements" based on surveys of 142 individuals in the province of Toledo with different psychosocial characteristics. The results indicate the organization of these individuals in two main clusters (sports and board games) and in others secondary groups -school games and audio-visual entertainment-. These findings must be tempered if we consider the psychosocial characteristics of the individuals. In this case is very important the variation of semantic networks due to the age factor and the sex factor.
\end{abstract}

KEY WORDS: Semantic Networks, games, psycholinguistic, lexical availability.

\section{Introducción}

Para dar cuenta de la organización del lexicón se han propuesto diversas teorías. Aunque en los años cincuenta y sesenta del siglo pasado el modelo de 
rasgos o componentes semánticos tuvo gran aceptación ${ }^{1}$, en la actualidad las más seguidas son la teoría de prototipos y la teoría de redes semánticas. Estas teorías no son totalmente excluyentes, pues presentan puntos de contacto.

La principal característica del modelo de prototipos consiste en no concebir nuestro diccionario mental a partir de categorías lógicas clásicas, como conjunto cerrado y ordenado formalmente. Aunque es una intuición relativamente lejana en el tiempo -sólo basta recordar el concepto de "aire de familia" del segundo Wittgenstein-, el apoyo moderno a esta forma de considerar el lexicón ha venido de la lógica difusa².

Para los seguidores de este punto de vista, cuya principal impulsora fue E. Rosch desde el campo de la psicología cognitiva ${ }^{3}$, el aprendizaje de términos nuevos se haría por comparación con un modelo cognitivo idealizado -el prototipo de la categoría- del que pueden aducirse ejemplares más o menos representativos, de modo que puede haber casos de organización prototípica con varios ejemplares adecuados (Coleman y Kay, 1981: 27). Resulta, pues, que el diccionario mental se estructuraría en conjuntos difusos de palabras que se agruparían en torno a diversos prototipos. Seguramente en español la categoría pájaros tendría como centro o prototipo a gorrión y en torno a él iríamos situando en un nivel muy cercano a golondrina, jilguero, etc. y más alejado a, por ejemplo, águila, buitre; y en la periferia del conjunto a aves como avestruz o pingüino.

Los defensores de la teoría de redes semánticas (Quillian, 1968) no niegan la existencia de palabras prototípicas, pero postulan que la semejanza cognitiva no es la única manera de organizar los significados sino que son muy importantes las diversas relaciones que se establecen entre palabras. Esas relaciones son fundamentalmente semánticas (relacionamos fuertemente alto y bajo porque son antónimos), pero también aparecen relaciones fonológicas (dentro de la serie relacionada semánticamente barco, avión, coche, camión es muy probable que estén más cerca en nuestro diccionario mental la pareja avión-camión por presentar un esquema silábico y acentual semejante) y gramaticales (en la serie profesor, alumno, escribir, explicar agruparemos por un lado profesor-alumno porque son sustantivos y, por otro, escribir-explicar porque son verbos).

1 Hoy en día sus seguidores han menguado considerablemente, sobre todo porque, como señalaba tempranamente Lyons (1977: 313): “...todavía está por demostrar que los componentes del sentido del tipo que los lingüistas tienden a invocar [...] desempeñen algún papel en la producción e interpretación de los enunciados lingüísticos. Y si no puede probarse una cierta validez psicológica en los componentes de sentido presuntamente más básicos, gran parte del atractivo del análisis componencial desaparece."

2 Para una historia de estas relaciones conviene consultar Mouré (1996).

3 Con trabajos ya clásicos como Rosch (1975 y 1978) o Rosch y Mervis (1975). 
De esta manera, el almacenamiento de las palabras en nuestra memoria iría conformando una intrincada e inmensa red donde los nudos serían las palabras que estarían unidas por multitud de relaciones.

Las pruebas aducidas por los defensores de la existencia de redes semánticas en el lexicón son clásicas: las pruebas de emparejamiento (Jenkins, 1970), en las que ante una palabra estímulo se pide a los encuestados que digan la primera palabra que les viene a la cabeza. Estos experimentos revelaron que las palabras de un mismo campo semántico están cerca; por ejemplo, el $75 \%$ de los encuestados une blanco con negro mientras nadie responde mar a una palabra estímulo como queso.

Se han aducido distintas objeciones a estas pruebas. Las más importantes son:

a) Es una prueba no natural (no refleja la normalidad de los actos de habla).

b) Se pregunta por una sola palabra, pero lo más probable es que las uniones sean múltiples y de distintas clases.

c) Como señala Aitchinson (1987: 73) "Can we build up a detailed mental map from these responses? Unfortunately not, in spite of the enormous amount of information available from Word association experiments". Parece, pues, imposible establecer redes semánticas naturales por la ingente cantidad de datos que se involucran en el proceso.

Aunque asumo que la dificultad es grande (Hernández Muñoz, 2006 y 2007), creo que los datos con los que trabajan los investigadores sobre léxico disponible pueden ayudar a determinar parcelas de la red semántica mental que nos permitan una aproximación a redes semánticas naturales ${ }^{4}$. Como se verá, estos datos pueden ayudarnos a solventar, en buena medida, las dificultades segunda y tercera que presentaban las pruebas de emparejamiento palabra a palabra.

El léxico disponible de un centro de interés es el conjunto de palabras que los hablantes tienen en el lexicón mental y cuyo uso está condicionado por el tema concreto de la comunicación. Las encuestas de disponibilidad léxica sirven para medir y valorar el tipo, cantidad y orden de preferencia de palabras que usa realmente un hablante en un contexto determinado.

Aunque en la ya numerosa bibliografía -Samper y Samper (2006) y www. dispolex.com para una revisión exhaustiva- sobre disponibilidad léxica prima el análisis sociolingüístico, no han faltado trabajos psicolingüísticos desde fecha relativamente temprana (Cañizal Arévalo, 1991), que se han visto

$4 \quad$ Ha de entenderse por redes semánticas naturales o reales las establecidas en el lexicón de un hablante o grupo de hablantes a partir de un corpus real. Redes semánticas como las de Wordnet o las usadas profusamente en Inteligencia Artificial son estáticas, no naturales. 
reforzados en los últimos tiempos (Echeverría y otros, 2008; Gómez Molina, 2009; Hernández Muñoz, 2006 y 2007; Manjón-Cabeza, 2008a y 2008b; Paredes García, 2006).

La metodología de las encuestas de disponibilidad ayuda en el intento de establecer redes semánticas por tres motivos principales:

a) Las encuestas de disponibilidad léxica permiten delimitar el campo. Sabido es que, al seleccionar centros de interés, se subdivide el lexicón en apartados que serán más manejables en cuanto a su volumen.

b) Este tipo de encuestas también permite acotar el número de palabras con el que trabajar. Es mucho más operativo intentar establecer redes semánticas con las palabras más disponibles y obviar aquellas con bajo índice de disponibilidad.

c) La tradición del trabajo con léxico disponible permite también contar con factores sociales que, quizá, tengan algo que decir en la configuración de las redes semánticas.

\section{Metodología}

\subsection{Muestra}

Para ejemplificar, en esta ocasión he trabajado con el corpus léxico obtenido de una muestra de 142 hablantes toledanos que fueron encuestados en 2007 en las localidades de Toledo, Olías del Rey, Yuncler, Tembleque y Robledo del Buey. Los informantes se tabularon según los siguientes factores sociales:

1. Sexo: 77 mujeres y 65 hombres.

2. Edad: veinticinco niños pertenecientes al tramo de edad comprendido entre los 5 y 11 años; 44 jóvenes, comprendidos entre los doce y los veinticinco años; 49 adultos (hasta 65 años); y veinticinco ancianos. Las encuestas de los niños más pequeños -entre cinco y ocho años inclusive- fueron orales, con un tiempo máximo de un minuto; al igual que la de los ancianos que presentaban dificultades escribanas. El resto hizo la tradicional encuesta escrita con un tiempo máximo de dos minutos.

3. Nivel sociocultural: 68 individuos fueron adscritos al nivel cultural bajo, 45 al nivel medio y veintiocho al nivel sociocultural alto. Para la adscripción se determinó un índice de nivel social y otro índice para el nivel cultural. El índice social tiene en cuenta la categoría laboral: 0-obreros, 1-autónomos sin empleados, 2-administración, 3-autónomos con empleados, 4-profesiones liberales y asimilados y 5-empresa- 
rios. Por su parte el índice cultural tomó en cuenta el nivel de estudios superado: 2-sin estudios, 3-estudios primarios, 4-secundaria y 5-estudios universitarios. La suma de ambos índices da un rango de valores que oscila entre el mínimo 2 y el máximo 10, de modo que distingo el nivel sociocultural bajo cuando el valor es 2, 3 ó 4, nivel medio cuando el valor es 5, 6 ó 7 y nivel sociocultural alto para los valores 8 , 9 ó 10. En el caso de los hablantes no independizados, si cursaban estudios obligatorios, el índice se calculó teniendo en cuenta el de sus padres; mientras que en el caso de estudiantes de etapas voluntarias -bachillerato y enseñanza universitaria- el proceder fue distinto ya que se mantuvo el índice social de los padres, pero el cultural fue el propio.

Tras la aplicación del programa Lexidisp elaborado por Francisco Moreno Fernández, José Enrique Moreno Fernández y Antonio J. García de las Heras ${ }^{5}$, obtuve un total de 457 lexías distintas, que se pueden consultar en ManjónCabeza (2009). De estas 457 unidades tomo en consideración las que suponen una frecuencia acumulada del 40\%, que -como es lógico-variarán según el factor estudiado. Para la totalidad de la muestra son treinta: fútbol, parchís, escondite, baloncesto, cartas, comba, cine, ajedrez, tenis, oca, dominó, pilla-pilla, leer, bailar, mus, música, corro de la patata, natación, play station, televisión, pasear, bicicleta, canicas, balonmano, damas, petanca, ordenador, tute, monopoly y solitario. Para el factor sexo son las veinte primeras, mientras que para los factores nivel sociocultural y edad el $40 \%$ de la frecuencia acumulada se alcanza con las primeras quince unidades.

Las unidades léxicas más disponibles para los distintos factores señalados se pueden consultar en las tablas 1 (disponibilidad léxica según factor sexo), 2 (disponibilidad según nivel sociocultural) y 3 (disponibilidad según el fac-

5 El programa Lexidisp usa la fórmula propuesta por López Chávez y Strassburger (1991) que pondera adecuadamente la frecuencia adquirida por una lexía con sus lugares de aparición en las listas. La fórmula es:

$D(P j)=\sum_{i=1}^{n} e^{-2.3}\left(\frac{I-1}{n-1}\right) \times \frac{f j i}{I_{1}}$

donde:

$\mathrm{D}(\mathrm{Pj})=$ disponibilidad de la palabra $\mathrm{j}$.

$\mathrm{n}$ = máxima posición alcanzada en el centro de interés.

$\mathrm{i}=$ número de posición.

$\mathrm{j}=$ índice de la palabra tratada.

$\mathrm{e}=$ número natural.

fji $=$ frecuencia absoluta de la palabra j en la posición i.

$\mathrm{I}_{1}=$ número de informantes que participaron en la encuesta. 
tor edad) de los Apéndices. Ha de observarse que esas son las lexías que tomamos como base para el establecimiento de las distintas redes semánticas.

\subsection{Cálculo de distancias entre palabras}

Para determinar la red semántica que forman estas palabras es necesario saber a qué distancia están unas de otras. Para ello seguimos varios pasos:

Primero: para cada informante se diferencian las palabras más disponibles de aquellas que se obvian en el estudio. Así, por ejemplo, el informante 20 actualizó: fútbol, voleibol, parchís, cartas, damas, ajedrez, pelota sentada, zapatilla por detrás, tenis, bicicleta, videoconsola, baloncesto, música, bailar, gallinita ciega, pídola, rayuela, mata[d]o y natación; de ellas, voleibol, pelota sentada, zapatilla por detrás, videoconsola, gallinita ciega, pídola, rayuela y mata[d]o no están entre las treinta más disponibles del grupo, de modo que hay que tener en cuenta el espacio que ocupan pero no se estudian como integrantes de la red.

Segundo: para cada informante se mide la distancia entre palabras y se les asigna un valor exponencial decreciente: si la palabra está contigua se le asigna un valor de 100; si hay una distancia de una palabra intermedia el valor será de 33,3; y si la distancia es de dos palabras intermedias, el valor será 11,1. Para la justificación de este proceder y detalles metodológicos suplementarios se puede consultar Manjón-Cabeza (2008a y 2008b).

Tercero: se suman las distancias entre palabras para el grupo social que nos interese y se establece la media de las distancias, pero esa media ha de ser ponderada $^{6}$ para evitar distorsiones ya que, por ejemplo, la probabilidad de que aparezca la unión entre fútbol y parchís es muy alta porque son palabras actualizadas por muchos individuos -72 y 55 casos, respectivamente-, mientras que la probabilidad de que aparezca la unión entre televisión y leer es mucho menor porque aparecen en menos individuos de la muestra -16 y 26 apariciones, respectivamente-. De este modo hay que tener en cuenta que el sumatorio de las distancias entre dos palabras habrá de ser dividido por el número de apariciones de la palabra con menor ocurrencia.

Así se obtiene el índice de distancias ${ }^{7}$ (ID) para, en este caso, la totalidad de la muestra, que aparece en la tabla 4 de los apéndices. Si la cifra se acerca

6 Es una de las diferencias entre la metodología aquí propuesta y la presentada por Echeverría y otros (2008).

7 El índice de distancias (ID) entre dos palabras se puede definir del siguiente modo:

$\operatorname{ID}(\mathrm{AB})=\frac{\sum_{\mathrm{i}}^{\mathrm{j}} d(A B)}{\mathrm{n}_{\mathrm{B}}}$ 
al 100, la relación es muy estrecha, mientras que si se acerca al cero, la relación es inexistente. Se observa, si seguimos con el ejemplo anterior, que la unión entre palabras que aparecen mucho como fútbol y parchís puede ser mucho más laxa $(4,44)$ que la que existe entre palabras de menor presencia, como televisión y leer $(29,16)$.

Para poder razonar con los datos es necesario establecer niveles de calidad entre las relaciones. Así pues, distingo:

1. Relaciones muy fuertes (entre 100 y 30 )

2. Relaciones fuertes (entre 20 y 30 )

3. Relaciones débiles (entre 15 y 20)

Ha de tenerse en cuenta que un índice de 30 significa estadísticamente que dos palabras se actualizan siempre próximas.

Los índices obtenidos se pueden trasladar a gráficos que intenten metaforizar la red semántica natural obtenida, aunque ha de tenerse en cuenta que redes naturales complejas implican gráficos complejos.

Como último aspecto metodológico conviene tener en cuenta que en este trabajo no se razona con la ausencia de relaciones, pero esto no quiere decir que no sea significativa. Por ejemplo, el índice de distancias entre mus y cartas es cero, al igual que el existente entre dos actividades que podríamos suponer próximas como leer y ajedrez.

\section{Resultados}

\subsection{Totalidad de la muestra}

Tras la selección de los datos significativos de la Tabla 4 (distancias para el total de la muestra) obtenemos la red semántica que aparece en la Figura 1, en la que con diferente trazo señalamos las uniones muy fuertes, fuertes y débiles.

A pesar de ser un campo léxico con mucha dispersión, podemos observar que la red semántica de los términos más disponibles está muy estructurada porque sólo hay una palabra que queda fuera de ella: canicas. Existen tres conglomerados (clústers) principales que vienen dados por la existencia de

donde:

ID = índice de distancia.

$\mathrm{d}=$ distancia.

A y B son las dos palabras entre las que se mide la distancia, siendo B la de menor aparición.

$\mathrm{n}_{\mathrm{B}}=$ número de apariciones de la palabra en cuestión.

$i$ y $j$ corresponde a número de informantes del grupo. 


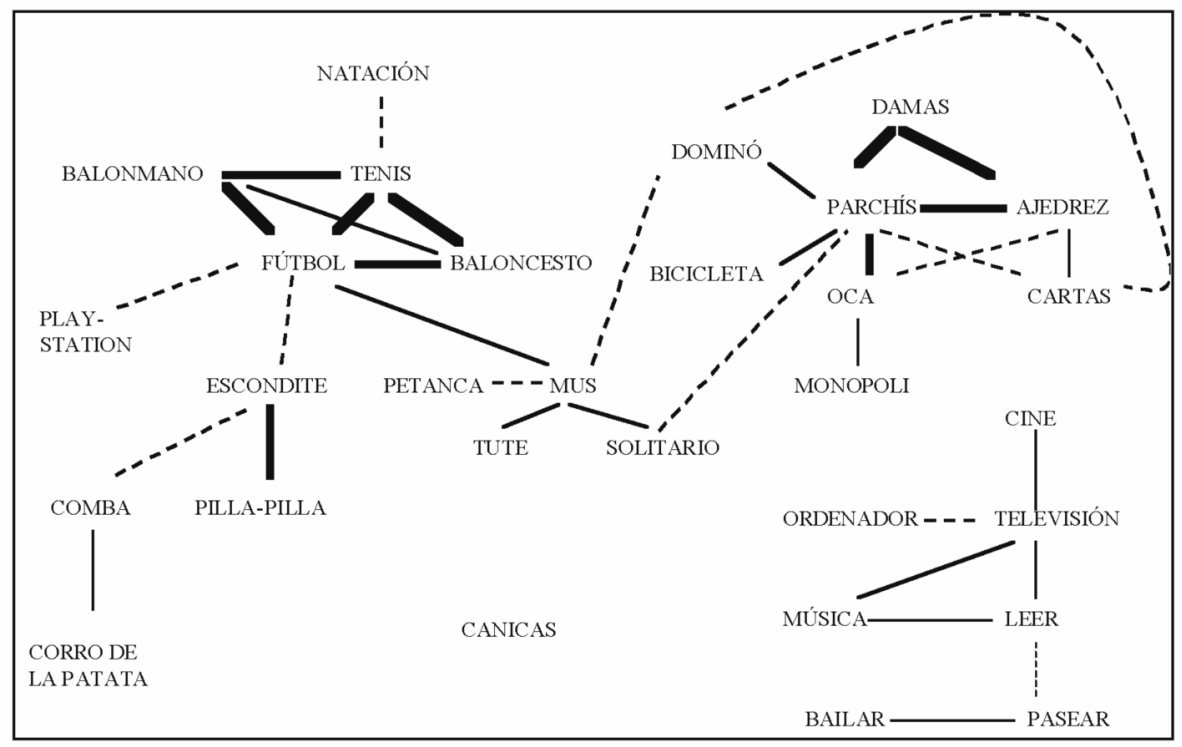

Figura 1. Red semántica para la totalidad de la muestra.

Leyenda -ID $>30$, - ID $>20$ y - - ID $>15$

uniones muy fuertes entre las palabras: deportes (fútbol, tenis, baloncesto y balonmano), juegos de mesa (parchís, oca, ajedrez y damas) y juegos infantiles (escondite y pilla-pilla). A ellos se suman otros conglomerados secundarios con uniones fuertes entre las palabras que los componen: diversiones audiovisuales (cine, televisión, música, leer), juegos de naipes (mus, tute, solitario) y una pareja de actividades formada por bailar y pasear.

Es importante anotar en este punto que los conglomerados primarios, formados por pocas palabras, se amplían conforme descendemos en el nivel de distancias. Por ejemplo, al grupo de los juegos infantiles altamente cohesionado (escondite y pilla-pilla) se le suman comba y corro de la patata. Lo mismo ocurre con los juegos de mesa que muestran un conglomerado principal (parchís, oca, ajedrez y damas) al que se unen en un segundo plano cartas, dominó y monopoly.

Estos conglomerados pueden estar aislados del resto, como ocurre con el de los entretenimientos audiovisuales o unirse con otros a través de determinados "puentes" entre palabras. Obsérvese cómo se relacionan directamente el grupo de los deportes con los juegos infantiles (con la unión débil entre fútbol y escondite) y con el de los juegos de cartas, en este caso con la unión fuerte entre mus y fútbol. También se establece una relación directa, como en principio cabría esperar, entre los juegos de naipes y los juegos de mesa. Sin 
embargo, no hay relación directa entre estos últimos y los deportes, a pesar de que algunos de sus integrantes están profusamente representados en las encuestas originarias.

Llama poderosamente la atención que haya palabras, incluso grupos de ellas, que muestran conexiones inesperadas, en el sentido que no casan por completo con nuestro conocimiento de la realidad. Quizá los casos más llamativos sean los de play-station que se une a fútbol o el del conglomerado secundario de juegos de cartas (mus, tute y solitario) que también se une a fútbol a través de mus. Creo que la explicación de estas uniones puede tener dos vertientes que no tienen porqué ser excluyentes.

La primera explicación tiene que ver con el hecho de que, aunque las conexiones son preferentemente referenciales, actúan también razones lingüísticas. Así, mus coincide con fútbol en el carácter tónico de la sílaba cuyo núcleo es la vocal $/ \mathrm{u} /$. Por otra parte, es evidente que el conocimiento metalingüístico de los hablantes -en este caso, sobre todo a través de la escrituraasocia fútbol y play-station como extranjerismos ${ }^{8}$.

La segunda explicación tiene que ver con la propia naturaleza de las redes complejas, como son las lingüísticas. En este punto hay que recordar que Albert y Barabási (2002) señalan que una de las características más importantes de diversas redes complejas reales (World Wide Web, redes de colaboraciones entre científicos, redes de llamadas telefónicas, etc.) consiste en que hay nudos tan fuertes en estas redes que son capaces de atraer a cualquier otro. Quiere decir que fútbol es el juego cognitivamente privilegiado, de modo que no sólo se asocia con otros deportes (baloncesto, tenis y balonmano) sino también con otras unidades referencialmente más alejadas. Debemos recordar en este punto que uno de los procesos básicos en el aprendizaje del vocabulario consiste en su reestructuración conforme avanzamos en la edad y en el caudal léxico: la estructura resultante no tiene porqué coincidir exactamente con el referente.

\subsection{Sexo}

Si extraemos los datos que consideramos significativos de las tablas 5 (distancias entre palabras para mujeres) y 6 (distancias para hombres), se obtienen las redes semánticas que se muestran en las figuras 2 y 3 .

8 Es cierto que no es del todo extraña la unión entre play-station y fútbol, puesto que existen juegos de este deporte para esa videoconsola, aunque creo que hubiéramos esperado una conexión más fuerte entre play-station y televisión, pero los datos nos demuestran que esa conexión es prácticamente inexistente pues obtenemos un valor de 0,69. 


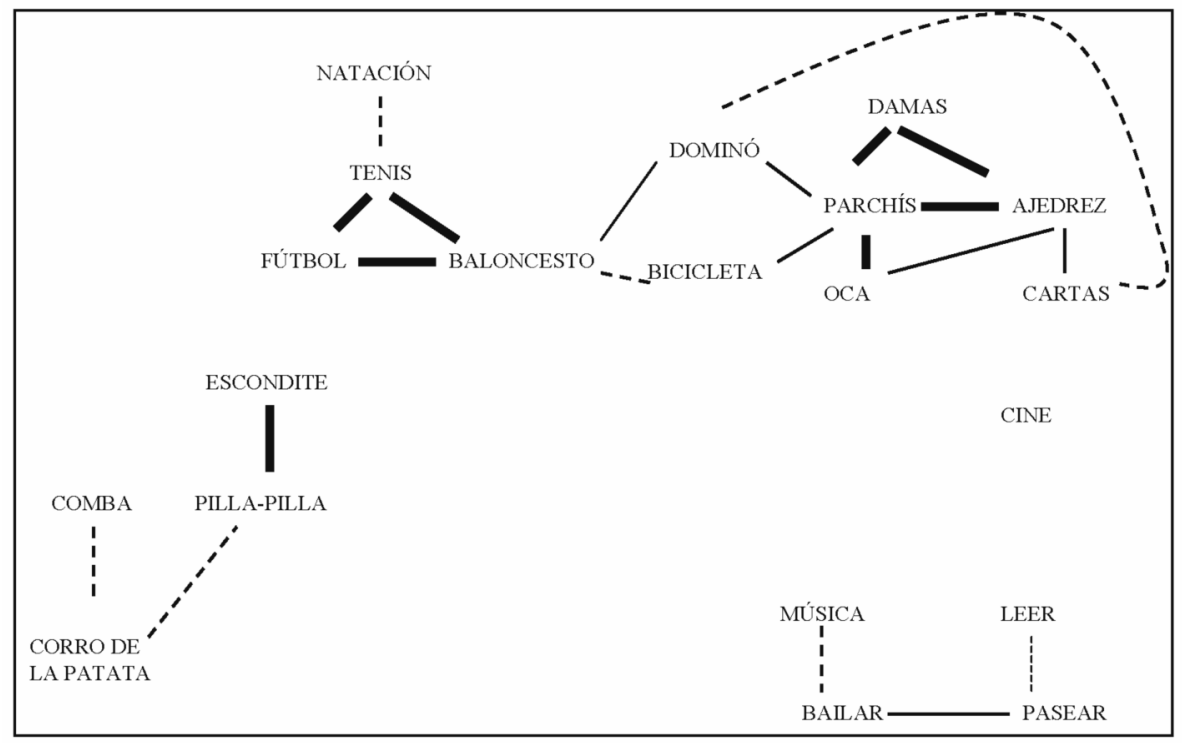

Figura 2. Red semántica de mujeres

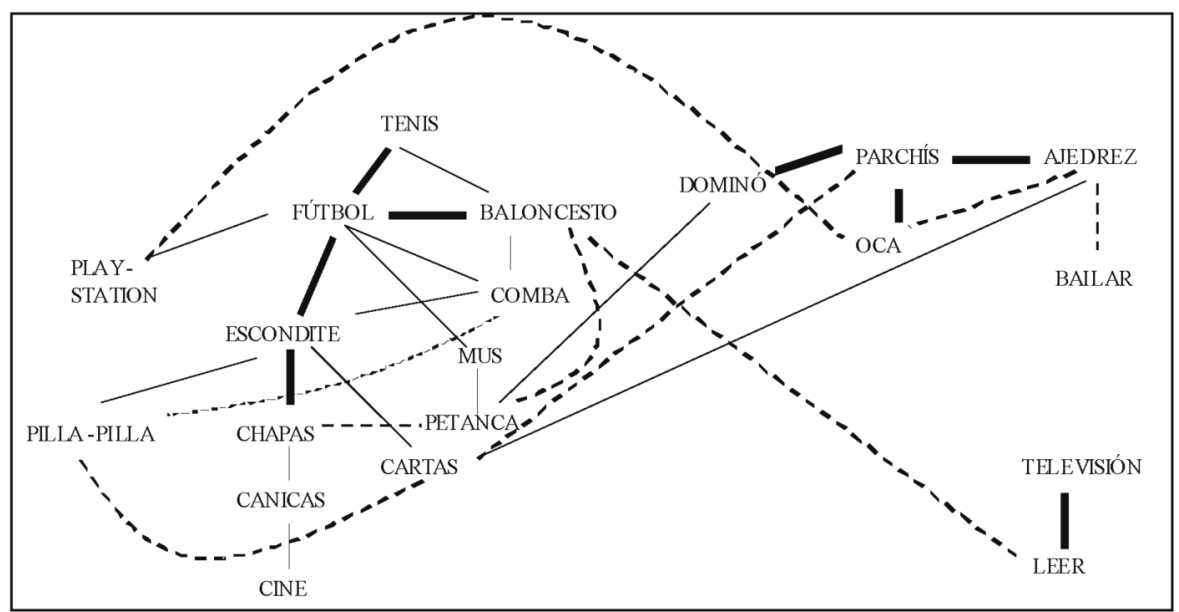

Figura 3. Red semántica de hombres

Aparte de las diferencias en el repertorio (corro de la patata, música, natación, bicicleta, pasear y damas son exclusivas de las mujeres, mientras que mus, petanca, chapas, canicas, play-station y televisión están más disponibles para los hombres) la organización semántica también presenta algunas discrepancias: 
a) Es evidente que las mujeres presentan una organización en conglomerados más nítida que los hombres, que presentan una malla mucho más complicada. De hecho, si consultamos las tablas 5 y 6 anotamos que las mujeres tienen 21 datos significativos (índice de distancia $\geq$ 15), mientras los hombres presentan 29.

b) Las mujeres tienen tres conglomerados muy cohesionados (deportes, juegos tradicionales y juegos de mesa) con pocas relaciones entre ellos. Observamos, asimismo, la presencia de un grupo secundario dominado por verbos (bailar, pasear, leer) al que se suma música; y una palabra que no se integra en la red: cine.

c) Los hombres, en cambio, unen en un único conglomerado los deportes y los juegos tradicionales que, a su vez, presenta múltiples relaciones con el conglomerado de los juegos de mesa. De este modo, se puede observar que, por ejemplo, cartas se une tanto a escondite como a ajedrez o que mus se une tanto a fútbol como a dominó. Estas múltiples uniones hacen que ninguna palabra quede fuera de la red ni ningún conglomerado quede libre.

d) El grupo de entretenimientos audiovisuales es distinto, dada la preeminencia de televisión en los varones. De los resultados obtenidos parece deducirse que leer es una actividad para las encuestadas -se une a pasear- mientras que para los hombres tiene un carácter más pasivo o estático dada su fuerte unión con televisión. No deja de ser interesante esta diferencia en la palabra leer, puesto que parece claro que en los hombres domina su particular referente estático, mientras en las mujeres parece que dominan razones lingüísticas en su inclusión en la red, pues, al fin y al cabo, leer y pasear son verbos con agente humano.

El análisis de estas configuraciones nos hace sospechar que los hombres, en este caso, presentan una organización que responde a la situación de las palabras alrededor del prototipo/mejor ejemplar (fútbol sobre todo, que ejerce de atractor privilegiado), mientras las mujeres tienen una organización más clusterizada o compartimentada. Quizá esto se vea reflejado en que los hombres tienen diez palabras que presentan tres o más conexiones con otras, mientras en las mujeres sólo observamos cuatro.

\subsection{Nivel Sociocultural}

Como en otros casos (Manjón-Cabeza 2008a, 2008b), el factor nivel sociocultural parece ser el que menos variaciones produce, como se puede observar en las figuras 4 (red semántica del nivel sociocultural bajo), 5 (red del nivel medio) y 6 (red del nivel alto), que se han elaborado a partir de los 
datos expuestos en las tablas 7 (índices de distancias del nivel sociocultural bajo), 8 (distancias del nivel sociocultural medio) y 9 (distancias del nivel alto). Incluso las diferencias de repertorio no son muy grandes puesto que tras consultar la tabla 2 (disponibilidad léxica según el nivel sociocultural) anotamos que hay nueve palabras comunes a los tres grupos y encontramos interrelaciones entre los tres niveles, es decir, palabras que aparecen en el nivel alto y bajo (pilla-pilla) y en el nivel medio y alto: leer y música.

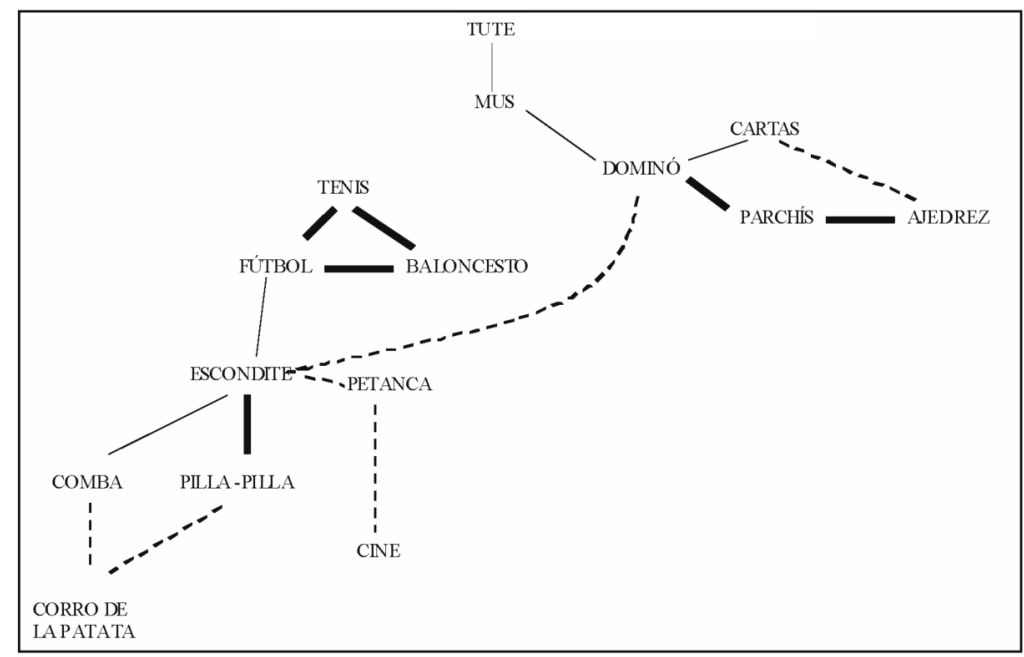

Figura 4. Red semántica del nivel sociocultural bajo

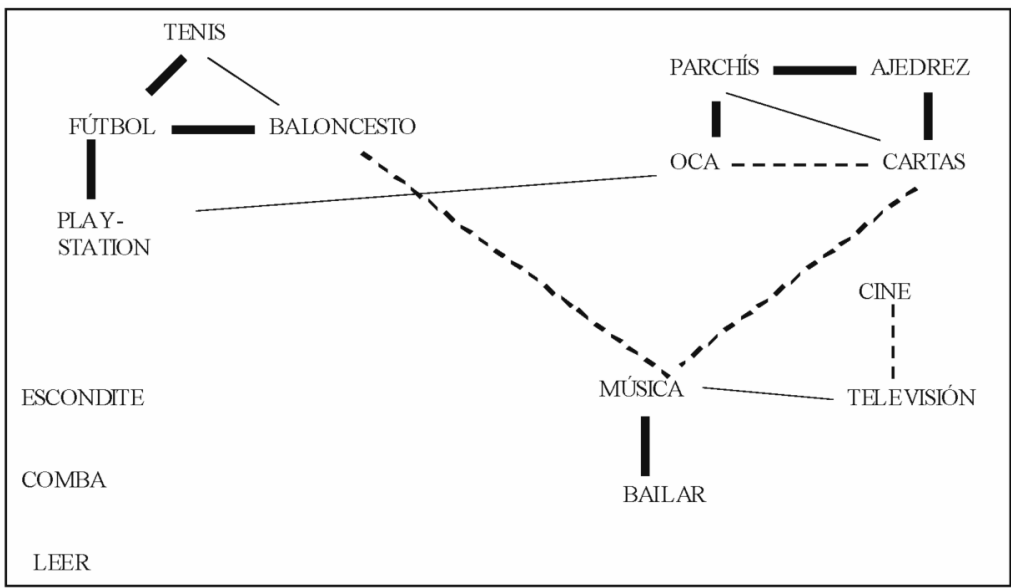

Figura 5. Red semántica del nivel sociocultural medio 


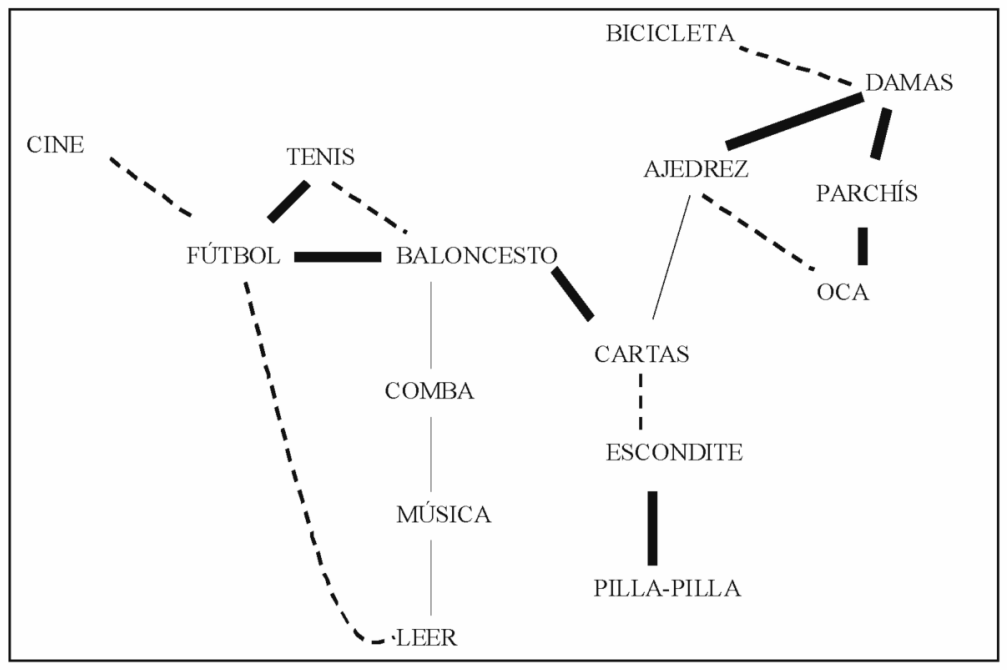

Figura 6. Red semántica del nivel sociocultural alto

Si sólo prestamos atención al repertorio podríamos caer en el error de considerar al nivel bajo como el que se particulariza frente a los otros, ya que tiene cinco palabras exclusivas (dominó, mus, corro de la patata, petanca y tute) frente a las dos de los otros niveles (televisión y play-station para el nivel medio, y damas y bicicleta para el nivel alto). Pero tras el análisis de los datos de distancias vemos que es el nivel medio el que presenta una configuración que más se aparta de los otros dos, ya que no tiene el conglomerado de los juegos infantiles -falta el tándem escondite-pilla-pilla- y potencia, en cambio, el de los entretenimientos audiovisuales. Se puede observar en la figura 5 que este último está formado por una pareja básica (música-bailar) a la que se une otra algo más secundaria (televisión y cine), de modo que observamos un conglomerado coherente según nuestro conocimiento de la realidad, frente a lo que ocurre en los otros dos grupos. Así, debe observarse el comportamiento errático de la palabra cine en los niveles bajo y alto, puesto que en el primero se une a petanca, mientras que en el segundo muestra relaciones con fútbol.

También es reseñable que sea el nivel medio el que presenta una red más limitada porque tres de sus palabras más disponibles (comba, escondite y leer) no se integran en la red semántica.

Los niveles bajo y medio se asemejan en el mantenimiento de los tres conglomerados básicos (deportes: fútbol, tenis, baloncesto; juegos de mesa, con centro en parchís, pero con distinta configuración en los dos niveles; y juegos tradicionales o escolares con la pareja ya vista formada por escondite y pilla-pilla). Pero se diferencian en: 
a) La configuración de los juegos tradicionales que es mínima en el nivel sociocultural alto (escondite y pilla-pilla), mientras que en el nivel bajo se amplía con comba y corro de la patata.

b) La ampliación de los juegos de mesa en el nivel bajo con la inclusión de mus y tute.

\subsection{Edad}

Se ha optado por la distinción de cuatro grupos de edad para poder observar de manera separada la configuración semántica en niños y ancianos, grupos frecuentemente desatendidos en las investigaciones sociolingüísticas sobre léxico disponible, pero imprescindibles si optamos por un acercamiento cognitivo9.

Las diferencias de repertorio que observamos en la tabla 3 (disponibilidad léxica según factor edad) son evidentes, ya que sólo encontramos cuatro palabras comunes para todos los tramos de edad: escondite, fútbol, comba y cartas.

Los grupos de edad extremos se singularizan por el número de palabras exclusivas. Así, los niños tienen cinco palabras exclusivas (pilla-pilla, balonmano, puzzles, cantar y bicicleta), los más mayores nada menos que siete: petanca, peonza, casitas, chito, pasear, corro y truque; mientras que jóvenes y adultos sólo tienen tres propias: música, ordenador y televisión para los jóvenes; y leer, damas y tres en raya para los adultos.

De los dos grupos de edad extremos, creo que los ancianos se singularizan más que los niños respecto a los otros grupos, puesto que se observa que los niños coinciden con los grupos intermedios de edad en un total de siete palabras, puesto que a las cuatro generales anteriormente señaladas se les unen parchís, baloncesto y tenis; en cambio, los ancianos comparten con los jóvenes y adultos un total de cinco palabras, ya que a las cuatro comunes sólo se le une cine. Esta separación del grupo de edad de mayor edad se puede ejemplificar con la ausencia de una palabra tan importante para los demás grupos como es parchís.

Las diferencias entre los grupos de edad quedan corroboradas si observamos los resultados obtenidos en los índices de distancias entre palabras, que se muestran en las tablas 10, 11, 12 y 13 (distancias para niños, jóvenes, adultos y ancianos; respectivamente). Los índices más significativos proporcionan unas redes semánticas que se muestran en las figuras 7 (red semántica de niños), 8 (red de jóvenes), 9 (red semántica de adultos) y 10 (red semántica de ancianos).

9 Con excepciones como las que encontramos en Borrego Nieto (2008). 


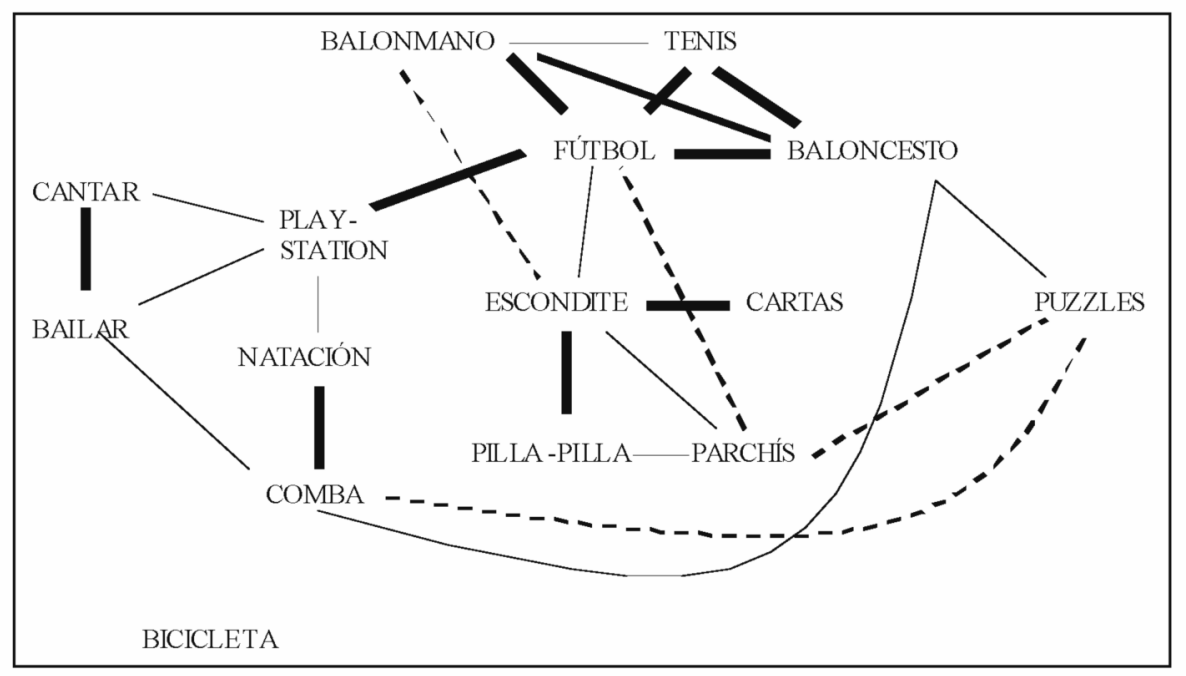

Figura 7. Red semántica de niños

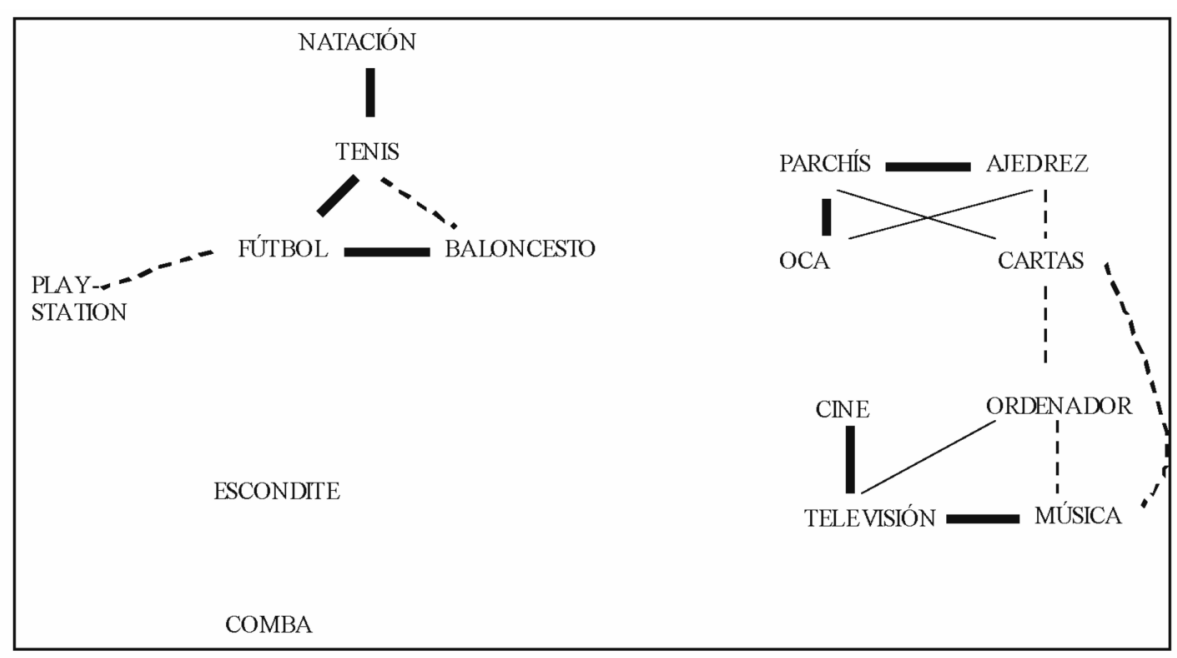

Figura 8. Red semántica de jóvenes 


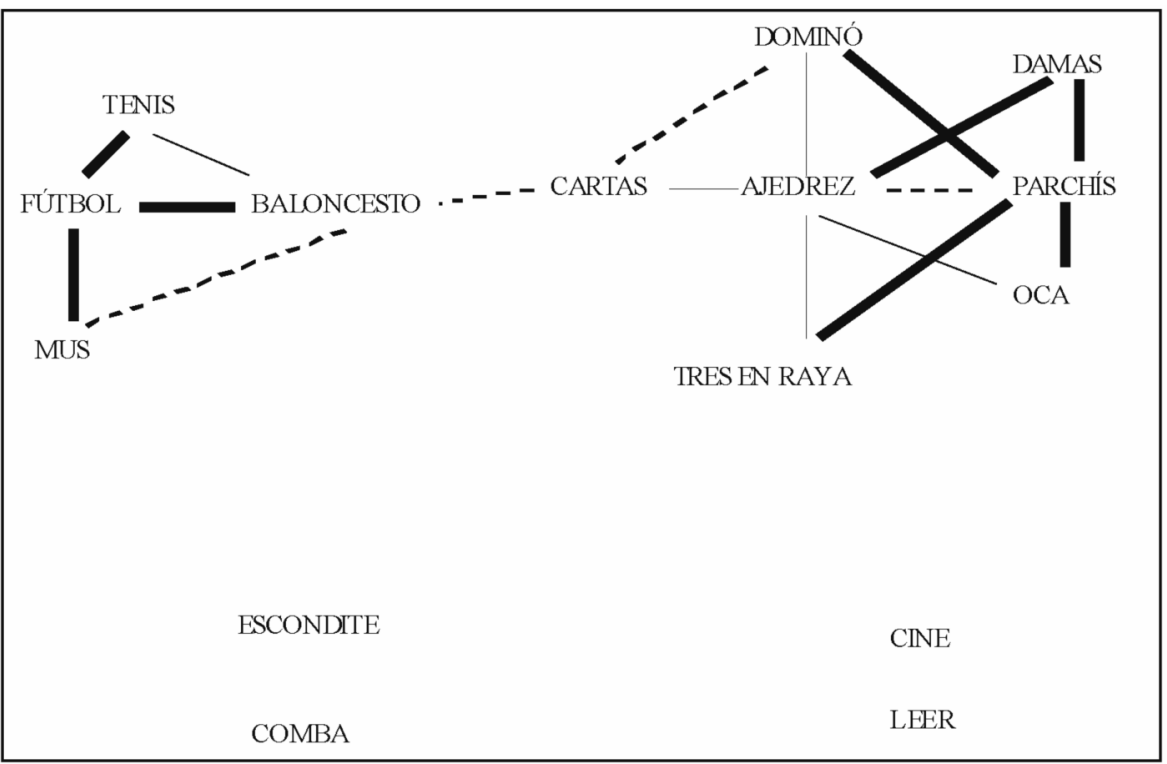

Figura 9. Red semántica de adultos

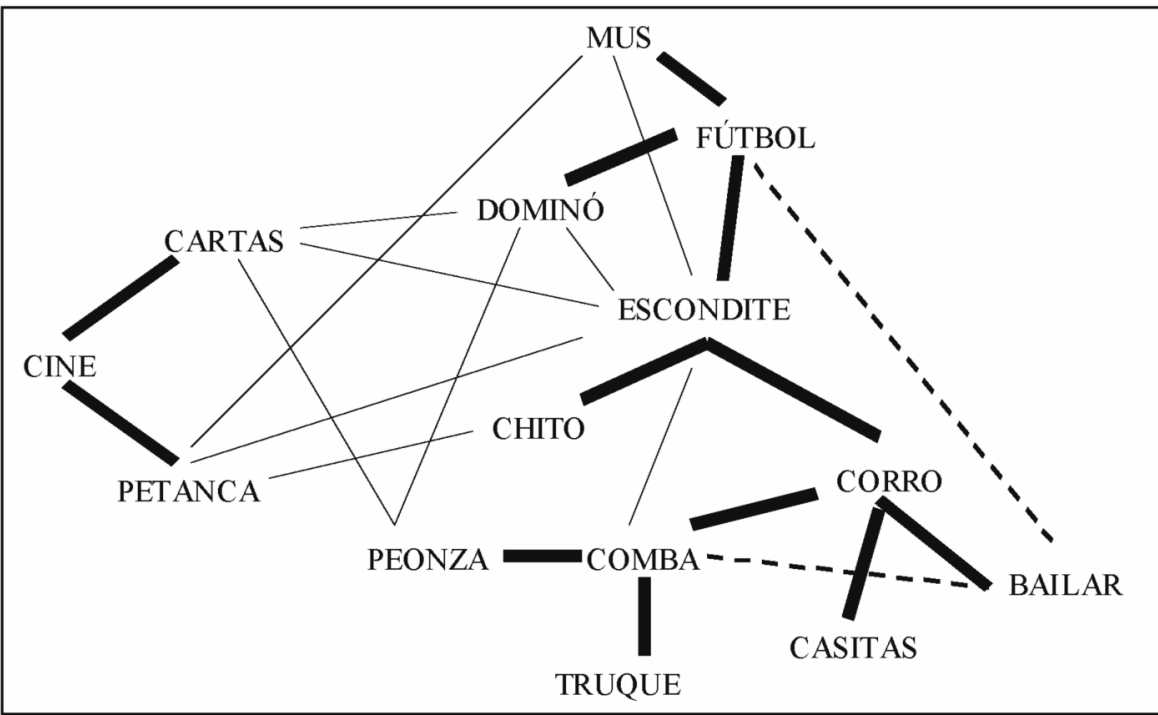

Figura 10. Red semántica de ancianos 
Como era de esperar por las diferencias de repertorio, el factor edad es muy significativo en cuanto a la variación de la configuración de las redes semánticas en este campo léxico. Esto es así por varios motivos:

a) Jóvenes y adultos se distinguen de niños y ancianos en la presencia de conglomerados más independientes: deportes -con centro en fútbol-y juegos de mesa, con parchís como palabra dominante; aunque se diferencian entre ellos en que los jóvenes presentan cohesionado el grupo de las diversiones audiovisuales (televisión, cine, música y ordenador), que no aparece como clúster en los adultos, aunque sí algunas unidades léxicas que no se integran en la red: cine y leer.

b) Niños y ancianos presentan una red mucho más intrincada en la que los grupos de palabras no presentan unas fronteras tan nítidas, sobre todo en el caso de los más mayores, puesto que los niños presentan un evidente y complejo conglomerado de deportes (fútbol, baloncesto, balonmano y tenis), ausente en el otro extremo de edad.

c) El caso de la configuración semántica de los más mayores (Figura 10) es especialmente complicado ya que observamos un conglomerado menor formado por cine, cartas y petanca-con difícil justificación referencial o lingüística- y un macroconglomerado formado por nada menos que once palabras. La situación se complica por dos motivos. El primero estriba en que las relaciones entre ambos conglomerados son muchas, fuertes y en diversas direcciones; así, por ejemplo, cartas se une a tres palabras del otro grupo: dominó, escondite y peonza. El segundo motivo reside en que es difícil decidir qué palabra es la central $^{10}$ en el macroconglomerado que venimos comentando, puesto que parece que tenemos cuatro candidatos: fútbol, escondite, corro y comba. En todos los demás gráficos presentados podemos señalar uno o dos centros, pero nunca tres o cuatro. Parece que estamos ante un macroconglomerado que apunta en la dirección de una organización difusa, muy alejada de la clusterización.

d) Resulta llamativo el cambio en la organización de los representantes de los juegos de mesa de los niños (parchís, cartas) y de los jóvenes (parchís, cartas, ajedrez y oca). En los más pequeños se asocian con los jue-

10 Es relativamente fácil determinar la centralidad de una palabra en un conglomerado por el número de conexiones muy fuertes que establece con otras palabras. Por ejemplo, en la figura 9 (red semántica de adultos) se puede observar que el conglomerado de los juegos de mesa es complejo, pero hay una palabra (parchís) que tiene cuatro conexiones muy fuertes con las demás, frente a las demás que tienen dos (damas) o una, caso de dominó, ajedrez, oca y tres en raya; por lo tanto, podemos señalar a parchís como centro del conglomerado. 
gos escolares del tipo de escondite y pilla-pilla; en cambio, en los jóvenes desaparece esa relación y constituyen un grupo aparte, es decir, asistimos a un ejemplo de cambio en la estructuración semántica según avanzamos en la edad. Parece ser que en los niños prima la visión unitaria de ciertos juegos propios, mientras que los jóvenes reestructuran su red separando tajantemente sus juegos y los juegos típicos de la infancia.

e) Los juegos escolares no desaparecen en los tramos intermedios de edad, pero las palabras que los designan (escondite y comba) no se integran en la red. Estamos, pues, ante palabras importantes en cuanto a su disponibilidad que nos dan pistas de una dirección en la reestructuración de la red: la posibilidad de la desaparición de un conglomerado sin necesidad de que desaparezcan sus representantes, como se puede observar en las figuras 8 y 9 .

f) Ya se ha comentado las particularidades de la configuración de los conglomerados en el grupo de mayor edad, pero debemos añadir que también presenta este grupo una red cualitativamente muy diferenciada de los otros ya que aparece una sola palabra representante de los deportes -fútbol, claro está- frente al mínimo de la triada fútbol, tenis y baloncesto de los otros tres grupos. Asimismo, es en este grupo de edad donde se acumulan los juegos más tradicionales con representantes léxicos más localistas como truque o chito, que se integran coherentemente en la red puesto que se unen a comba y escondite, respectivamente. Como ya se ha señalado, no deja de ser significativo que juegos infantiles como escondite, corro y comba constituyan centros de conglomerado para los más mayores.

\section{Conclusiones}

Frente al pesimismo metodológico que señalaba la imposibilidad del establecimiento de redes semánticas naturales, creo que la tradición de los métodos derivados de la disponibilidad léxica pueden ayudar a adentrarse en el lexicón real, aunque sea por parcelas.

En este sentido es necesario partir del estudio del repertorio del léxico disponible, aunque no es suficiente. Debemos completar la metodología de la disponibilidad con algún tipo de determinación de las relaciones entre las unidades léxicas, como el aquí propuesto. Así, por ejemplo, en nuestra muestra aparecen en los dos primeros lugares fútbol y parchís, pero podemos comprobar que su relación es inexistente, con un índice de distancias (tabla 4) prácticamente despreciable: 4,44. Por el contrario, la primera palabra dispo- 
nible (fútbol) tiene uno de sus índices de distancias más sobresaliente $(49,62)$ con la que aparece en el puesto vigesimosegundo: balonmano.

El análisis de las distancias de las unidades léxicas de la muestra estudiada viene a corroborar sólo en parte los resultados de las antiguas pruebas de emparejamiento, ya que los conglomerados típicos que se obtenían con esa metodología ${ }^{11}$ eran de dos o tres palabras -Coleman (1964), Jenkins (1970), Howard y otros (1981), Aitchinson (1987)-, mientras que nuestros resultados ofrecen casos más complejos. De este modo, si sólo razonamos con las uniones más fuertes y repasamos los distintos grupos estudiados anotamos veintiocho conglomerados en total. De ellos, observamos:

a) Ocho conglomerados formados por parejas de palabras, caso de escondite y pilla-pilla para la totalidad de la muestra (figura 1), mujeres (figura 2), nivel sociocultural bajo (figura 4) y nivel sociocultural alto (figura 6).

b) Ocho grupos formados por tres palabras, como escondite, pilla-pilla y cartas en los niños (figura 7) o fútbol, tenis y baloncesto en las redes semánticas de las mujeres (figura 2) y del nivel sociocultural bajo (figura 4).

Pero debemos ampliar esa lista con:

a) Nueve conglomerados de cuatro palabras como fútbol, tenis, baloncesto y balonmano para el total de la muestra (figura 1), fútbol, tenis, baloncesto y natación para los jóvenes (figura 8) o fútbol, tenis, baloncesto y mus en los adultos (figura 9).

b) Dos de cinco unidades, casos de fútbol, baloncesto, tenis, escondite y chapas en los hombres (figura 3) y fútbol, baloncesto, tenis, balonmano y play-station en los niños (figura 7).

c) El peculiar conglomerado de once palabras del grupo de ancianos (figura 10) formado por mus, fútbol, dominó, escondite, chito, corro, comba, peonza, truque, casitas y bailar.

Tras el análisis de los datos se comprueba que hay dos tipos principales de configuración de la red semántica, que he denominado modelo prototípico y modelo clusterizado, con estadios intermedios, por supuesto. El modelo prototípico -como los de hombres (figura 3), niños (figura 7) y ancianos (figura 10) - se caracteriza por presentar conglomerados con muchas unidades léxicas, múltiples relaciones entre los conglomerados e integración en la red de todas las palabras. En cambio, el modelo clusterizado -como los de las mujeres (figura 2) y jóvenes (figura 8)- tiene tendencia a los conglomerados

11 Si se pide a los encuestados sólo una palabra como respuesta a un estímulo, parece evidente que resultaría dificilísimo justificar estadísticamente la existencia de conglomerados con cuatro o más palabras. 
formados por pocas palabras, aislados entre sí y con unidades que no se integran en la red.

A falta de posteriores estudios, no deja de ser atractiva la hipótesis de que distintos factores psicosociales influyen en la distinta estructuración del lexicón. Esos factores son de distinto tipo: desde la naturaleza del campo semántico en cuestión, pasando por la existencia o no de un nudo absolutamente dominante, como ocurre con fútbol en los hombres, hasta la reestructuración por aprendizaje. Este último caso queda patente si observamos los cambios operados entre la red semántica de los niños, la de jóvenes y la de adultos, en las que se pueden observar las siguientes posibilidades:

a) Desaparición de conglomerados, a pesar de que alguna de las palabras que lo formaban sigue siendo altamente disponible para el grupo. Es lo que sucede con el conglomerado básico de los juegos infantiles (escondite-pilla-pilla) de la figura 7, que desaparece en los jóvenes y adultos (figuras 8 y 9), a pesar de la importancia de escondite, que ya no se integra en la red.

b) Migración de unidades de un conglomerado a otro. Obsérvese el caso de natación, que en los niños se une preferentemente a comba (figura 7), frente a lo que observamos en la figura 8 en la que natación aparece integrada en el conglomerado de los deportes.

c) Desaparición de palabras y, por tanto, reestructuración del grupo. Es el caso del grupo infantil de los deportes, constituido por fútbol, baloncesto, tenis y balonmano. En los jóvenes esta última palabra desaparece ${ }^{12}$.

d) Aparición de nuevas palabras e integración en algún clúster preexistente, como podemos observar que ocurre con mus, que aparece en los adultos (figura 9) y que se integra en el conglomerado de los deportes a través de su fuerte unión con fútbol.

Debe observarse que en los párrafos que anteceden no he razonado con ejemplos de la figura 10 (red semántica de ancianos) puesto que es muy diferente de los otros grupos, tanto en las unidades léxicas que la componen, como en su estructuración altamente difusa. Borrego Nieto (2008) constata la separación de este grupo de edad de los demás. Estamos, sin duda, ante un grupo con cultura léxica propia, que determina una organización particular.

Para el centro de interés que nos ocupa -juegos y diversiones- los conglomerados básicos se explican mayoritariamente por factores referenciales que, en algún caso, deben matizarse con condicionamientos lingüísticos, ya

12 La situación del conglomerado es algo más compleja, pues recuérdese que natación se integra en el grupo desde otro anterior y, además, en los niños aparece una muy fuerte unión entre fútbol y play-station que tiende a perder importancia en los jóvenes. 
sean categoriales (verbos que se suelen agrupar como bailar, pasear, cantar...), ya sean fonéticos (la extraña y recurrente unión entre mus y fútbol podría ser un ejemplo), sin desdeñar los condicionados por la escritura (caso de la repetida unión de play-station con fútbol).

Dado el carácter del campo estudiado no se pueden extraer conclusiones acerca de la presencia en nuestros datos de relaciones semánticas básicas ${ }^{13}$, excepto la de hiperonimia. Es relevante en este sentido el comportamiento de cartas, ya que aparece en todos los grupos estudiados. En buena parte de ellos -sirva de ejemplo la figura 5 que muestra la red para el nivel sociocultural medio- no aparece ningún posible hipónimo, luego parece lógico que se integre por proximidad referencial en el conglomerado de los juegos de mesa, junto con, en este caso, oca, parchís y ajedrez. Pero tenemos algunos grupos en los que sí aparecen posibles hipónimos, como mus y tute para el nivel sociocultural bajo (figura 4). Lo más llamativo es que en ningún caso cartas se relaciona con algún juego de naipes concreto, ni siquiera con uniones débiles. Los datos, por tanto, demuestran que no existe relación cognitiva de hiperonimia cartas-mus o cartas-tute.

Lo anterior viene a subrayar la diferencia entre las redes semánticas naturales o reales de las estáticas. Sin duda, desde un punto de vista teórico, todos propondríamos la existencia de una relación de hiperonimia entre cartas y mus, pero esa relación, al menos en la muestra analizada, no es operativa en la mente de los hablantes.

En definitiva, creo que el estudio de este tipo de datos ofrece un acercamiento más realista a la organización mental de léxico que los acercamientos clásicos ya comentados, sobre todo porque el enfoque psicolingüístico no excluye el sociolingüístico: el lexicón tiene una vertiente individual y otra social, que deben ser investigadas conjuntamente.

\section{Referencias bibliográficas}

Aitchinson, J. (1987): Words in the Mind. An introduction to the Mental Lexicon. Oxford (UK) y Cambridge (USA), Blackwell.

Albert, R. y A. L. Barabási (2002): "Statistical mechanics of complex networks", Reviews of Modern Physics, 74, 1, págs. 47-95.

Borrego Nieto, J. (2008): "Edad y culturas léxicas". En Arnal Purroy, M.L. (ed.): Estudios sobre disponibilidad léxica en los jóvenes aragoneses. Diputación de Zaragoza, págs. 227-244.

13 Para otros campos, como el de los colores -Manjón-Cabeza (2008b)-, es determinante la relación de antonimia o pseudoantonimia con uniones extraordinariamente fuertes en pares como blanco-negro y oro-plata. 
Cañizal Arévalo, A. M. (1991): "Redes semánticas y disponibilidad léxica en el español de escolares mexicanos". En C. Hernández y otros: El español de América, II. Valladolid, Junta de Castilla y León, págs. 631-641.

Coleman, E. B. (1964): "Supplementary report: On the combination of associative probabilities in linguistic contexts", Journal of Psychology, 57, págs. 95-99.

Coleman, L. y P. Kay (1981): "Prototype Semantics: the English verb lie", Language, 57,1 , págs. 26-44.

Echeverría, M., R. Vargas, P. Urzúa y R. Ferreira (2008): "DispoGrafo: una nueva herramienta computacional para el análisis de relaciones semánticas en el léxico disponible", Revista de lingüística teórica y aplicada, 46, I, págs. 81-91.

Gómez Molina, J. R. (2009): "Una aplicación psicolingüística de la disponibilidad léxica: la categoría nocional 'animales". En La Lingüística como reto epistemológico y como acción social. Estudios dedicados al profesor Ángel López. Madrid, Arco Libros, págs. 1047-1060.

Hernández Muñoz, N. (2006): Hacia una teoría cognitiva integrada de la disponibilidad léxica: el léxico disponible de los estudiantes castellano-manchegos. Salamanca, Univ. de Salamanca.

Hernández Muñoz, N., C. Izura y W. E. Andrew (2007): "Cognitive aspects of lexical availability", European Journal of Cognitive Psychology, 18:5, págs. 730-755.

Howard, D.V., M. P. McAndrews and M. I. Lasaga (1981): "Semantic priming of lexical decisions in young and old adults", Journal of Gerontology, 36, págs. 707-714.

Jenkins, J. J. (1970): "The 1952 Minnesota word association norms". En L. Postman and G. Keppel: Norms of word associations. New York, Academic Press.

López Chávez, J. y C. Strassburger (1991): "Un modelo para el cálculo de disponibilidad léxica individual”. En H. López Morales (ed.): La enseñanza de la lengua materna. Actas del II Seminario internacional sobre Aportes de la lingüística a la enseñanza de la lengua materna. Río Piedras, Univ. de Puerto Rico, págs. 99-112.

Lyons, J. (1977): Semántica. Teide, Barcelona, 1980.

Manjón-Cabeza Cruz, A. (2008a): "Determinación de redes semánticas naturales por medio de encuestas de disponibilidad léxica", Actas del VIII Congreso Nacional de Lingüística General. Madrid, ed. en CD-ROM, págs. 1169-1188.

Manjón-Cabeza Cruz, A. (2008b): "Redes semánticas naturales en escolares de 5 a 16 años: los colores", Docencia e investigación, 33, págs. 149-177.

Manjón-Cabeza Cruz, A. (2009): "Léxico disponible de los juegos y diversiones en Toledo", Docencia e investigación, 34, págs. 127-144.

Mouré, T. (1996): La alternativa no discreta en lingüística. Una perspectiva histórica y metodológica. Santiago de Compostela, Universidad de Santiago de Compostela.

Paredes García, F. (2006): “Aportes de la disponibilidad léxica a la psicolingüística: una aproximación desde el léxico del color”, Lingüística, 18, págs. 19-55.

Quillian, M. R. (1968): "Semantic Memory". En Minsky, M. (ed.): Semantic Information Processing. Cambridge (Mass.), MIT Press.

Rosch, E. (1975): "Human Categorization". En N. Warren (ed.): Advances in Cross Cultural Psychology. London, Academic Press, págs. 125-141. 
Rosch, E. (1978): "Principles of categorization". En E. Rosch y B. Lloyd (eds.): Cognition and Categorization. New Jersey, Lawrance Erlbaum Ass. Pub., págs. 27-48.

Rosch, E. y C. Mervis (1975): "Family resemblances: studies in the internal structure of categories", Cognitive Psychology, 7, págs. 573-605.

Samper Padilla, J.A. y M. Samper Hernández (2006): "Aportaciones recientes de los estudios de disponibilidad léxica”, LynX, 5, págs. 5-95.

www.dispolex.com (3-05-2010).

\section{Apéndices}

\begin{tabular}{|l|l||l|l|}
\hline Mujeres & Hombres \\
\hline $\mathrm{n}^{\mathbf{o}}$ & Palabra & $\mathrm{n}^{\circ}$ & Palabra \\
\hline 1 & parchís & 1 & fútbol \\
\hline 2 & escondite & 2 & baloncesto \\
\hline 3 & comba & 3 & escondite \\
\hline 4 & fútbol & 4 & parchís \\
\hline 5 & cartas & 5 & cartas \\
\hline 6 & cine & 6 & tenis \\
\hline 7 & oca & 7 & mus \\
\hline 8 & corro de la patata & 8 & ajedrez \\
\hline 9 & baloncesto & 9 & dominó \\
\hline 10 & ajedrez & 10 & cine \\
\hline 11 & pilla-pilla & 11 & bailar \\
\hline 12 & leer & 12 & petanca \\
\hline 13 & tenis & 13 & chapas \\
\hline 14 & música & 14 & canicas \\
\hline 15 & natación & 15 & leer \\
\hline 16 & bailar & 16 & play-station \\
\hline 17 & bicicleta & 17 & comba \\
\hline 18 & dominó & 18 & televisión \\
\hline 19 & pasear & 19 & oca \\
\hline 20 & damas & 20 & pilla-pilla \\
\hline
\end{tabular}

Tabla 1. Disponibilidad léxica según factor sexo (veinte primeras lexías)

\begin{tabular}{|l|l|l|l||l|l|}
\hline \multicolumn{2}{|l|}{ nivel bajo } & \multicolumn{3}{l|}{ nivel medio } & \multicolumn{3}{l|}{ nivel alto } \\
\hline $\mathrm{n}^{\circ}$ & Palabra & $\mathrm{n}^{\circ}$ & Palabra & $\mathrm{n}^{\circ}$ & Palabra \\
\hline 1 & fútbol & 1 & fútbol & 1 & fútbol \\
\hline 2 & escondite & 2 & parchís & 2 & escondite \\
\hline 3 & comba & 3 & baloncesto & 3 & parchís \\
\hline 4 & parchís & 4 & cartas & 4 & ajedrez \\
\hline 5 & baloncesto & 5 & escondite & 5 & pilla-pilla \\
\hline 6 & cartas & 6 & ajedrez & 6 & oca \\
\hline 7 & tenis & 7 & bailar & 7 & cine \\
\hline 8 & cine & 8 & oca & 8 & baloncesto \\
\hline 9 & dominó & 9 & cine & 9 & leer \\
\hline 10 & mus & 10 & leer & 10 & damas \\
\hline 11 & corro de la patata & 11 & tenis & 11 & tennis \\
\hline 12 & ajedrez & 12 & comba & 12 & bicicleta \\
\hline 13 & petanca & 13 & televisión & 13 & comba \\
\hline 14 & pilla-pilla & 14 & música & 14 & música \\
\hline 15 & tute & 15 & play-station & 15 & cartas \\
\hline
\end{tabular}

Tabla 2. Disponibilidad léxica según factor nivel sociocultural (quince primeras lexías) 


\begin{tabular}{|c|c|c|c|c|c|c|c|}
\hline \multicolumn{2}{|c|}{ primer nivel } & \multicolumn{2}{|c|}{ segundo nivel } & \multicolumn{2}{|c|}{ tercer nivel } & \multicolumn{2}{|c|}{ cuarto nivel } \\
\hline$n^{\circ}$ & Palabra & $\mathrm{n}^{\circ}$ & Palabra & $\mathrm{n}^{\circ}$ & Palabra & $n^{\circ}$ & Palabra \\
\hline 1 & fútbol & 1 & fútbol & 1 & parchis & 1 & escondite \\
\hline 2 & escondite & 2 & parchís & 2 & fútbol & 2 & comba \\
\hline 3 & baloncesto & 3 & baloncesto & 3 & cartas & 3 & fútbol \\
\hline 4 & comba & 4 & escondite & 4 & ajedrez & 4 & cartas \\
\hline 5 & pilla-pilla & 5 & tenis & 5 & cine & 5 & dominó \\
\hline 6 & parchís & 6 & música & 6 & leer & 6 & petanca \\
\hline 7 & play-station & 7 & cartas & 7 & baloncesto & \begin{tabular}{|l|}
7 \\
\end{tabular} & peonza \\
\hline 8 & balonmano & 8 & cine & 8 & escondite & 8 & bailar \\
\hline 9 & puzzles & 9 & ajedrez & 9 & oca & 9 & cine \\
\hline 10 & cantar & 10 & oca & 10 & damas & 10 & casitas \\
\hline 11 & tenis & 11 & ordenador & 11 & comba & 11 & mus \\
\hline 12 & bicicleta & 12 & comba & 12 & dominó & 12 & chito \\
\hline 13 & bailar & 13 & televisión & 13 & mus & 13 & pasear \\
\hline 14 & natación & 14 & play-station & 14 & tres en raya & 14 & corro \\
\hline 15 & cartas & 15 & natación & 15 & tenis & 15 & truque \\
\hline
\end{tabular}

Tabla 3. Disponibilidad léxica según factor edad

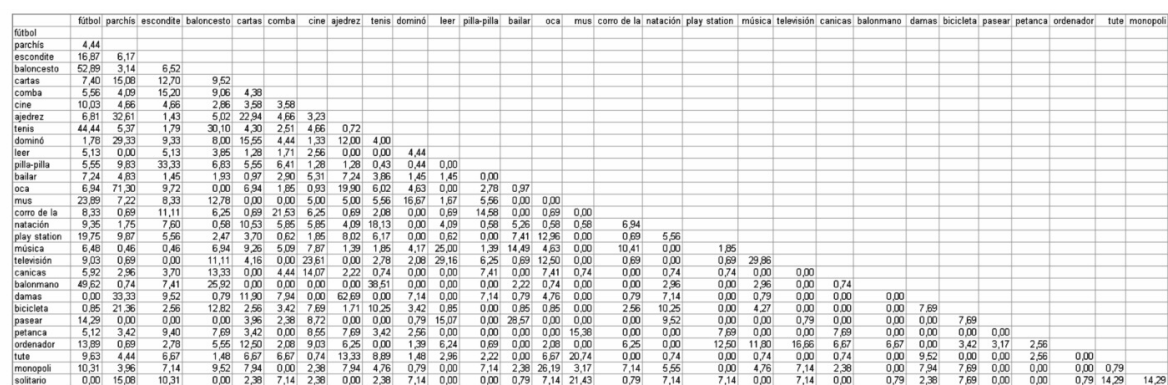

Tabla 4. Distancias para la totalidad de la muestra

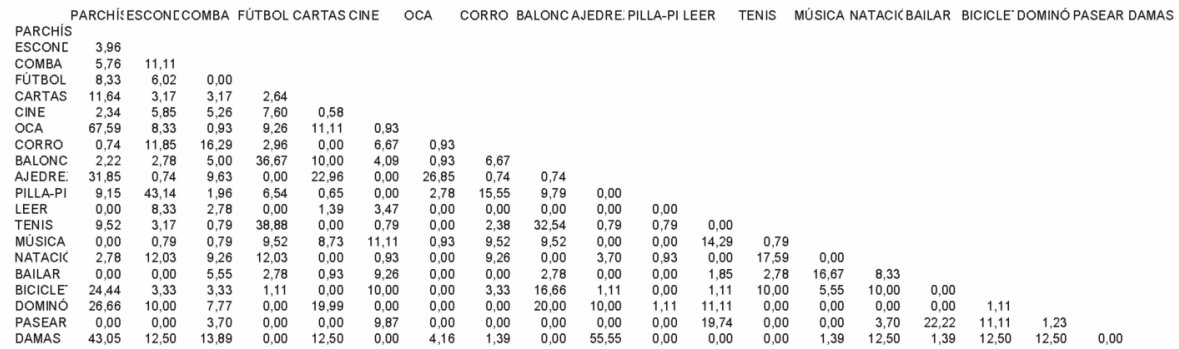

Tabla 5. Distancias para mujeres 


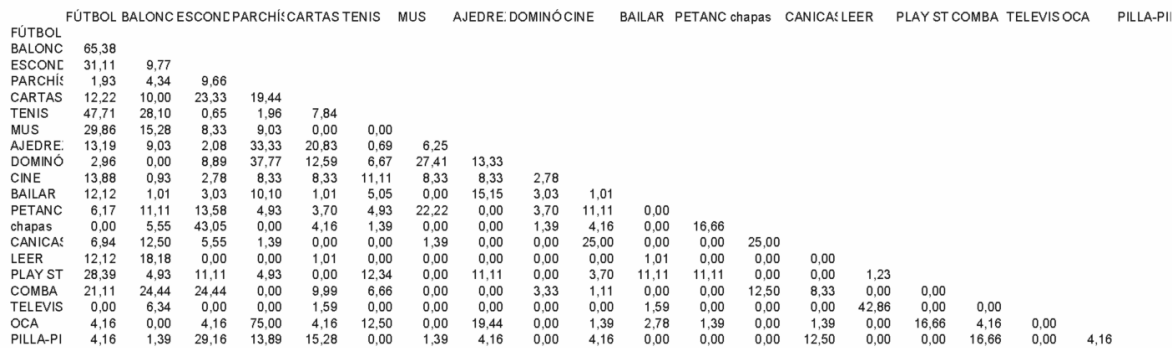

Tabla 6. Distancias para hombres



Tabla 7. Distancias para el nivel sociocultural bajo



Tabla 8. Distancias para el nivel sociocultural medio

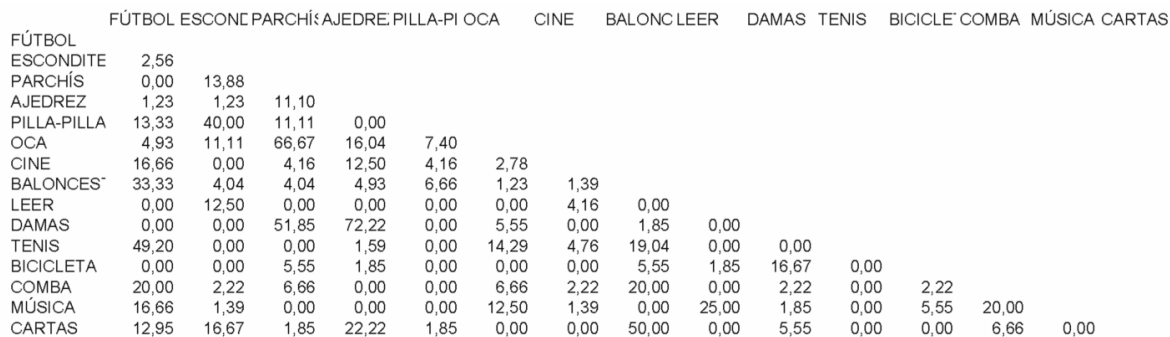

Tabla 9. Distancias para el nivel sociocultural alto 
FÚTBOL

FÚTBOL ESCONCBALONCCOMBA PILLA-PI PARCHISPLAY STBALONMPUZZLEミCANTARTENIS BICICLE BAILAR NATACIKCARTAS

ESCONDITE $\quad 23,33$

BALONCESTI $\quad 40,39 \quad 9,09$

$\begin{array}{lrrr}\text { COMBA } & 1,23 & 11,11 & 22,22\end{array}$

$\begin{array}{lllll}\text { PILLA-PILLA } & 12,34 & 51,84 & 11,11 & 7,40\end{array}$

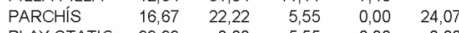

$\begin{array}{lllllll}\text { PLAY STATIC } & 33,33 & 0,00 & 5,55 & 0,00 & 0,00 & 1,85\end{array}$

$\begin{array}{lrrrrrrrr}\text { BALONMANC } & 33,32 & 16,67 & 35,18 & 1,85 & 0,00 & 0,00 & 0,00 & \\ \text { PUZZLES } & 7,40 & 0,00 & 22,22 & 16,67 & 1,85 & 16,67 & 5,55 & 0,00\end{array}$

$\begin{array}{lrrrrrrrr}\text { PUZZLES } & 7,40 & 0,00 & 22,22 & 16,67 & 1,85 & 16,67 & 5,55 & 0,00 \\ \text { CANTAR } & 0,00 & 2,22 & 0,00 & 20,00 & 0,00 & 0,00 & 20,00 & 0,00\end{array}$

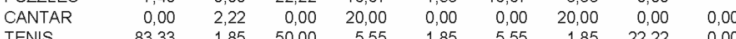

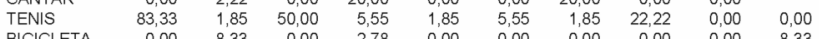

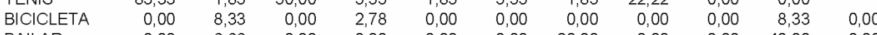

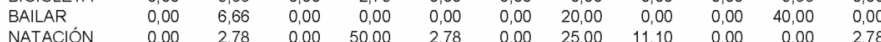

$\begin{array}{lrrrrrrrrrrrrr}\text { CARTAS } & 0,00 & 33,33 & 0,00 & 50,00 & 2,78 & 0,00 & 25,00 & 11,10 & 0,00 & 0,00 & 2,78 & 8,33 & 0,00 \\ \text { CA, } & 3,70 & 11,10 & 0,00 & 0,00 & 0,00 & 0,00 & 0,00 & 0,00 & 0,00 & 0,00\end{array}$

Tabla 10. Distancias para niños

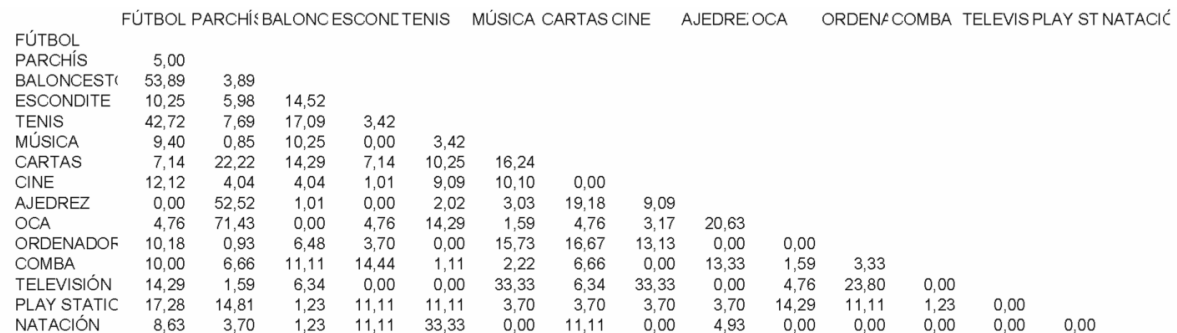

Tabla 11. Distancias para jóvenes

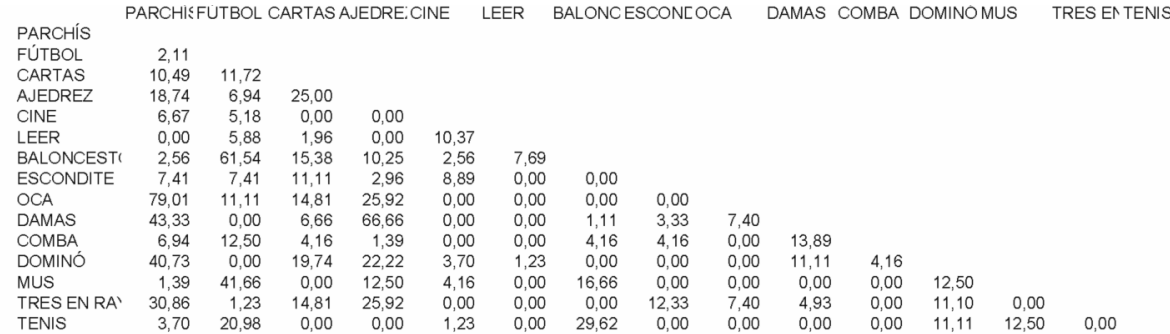

Tabla 12. Distancias para adultos

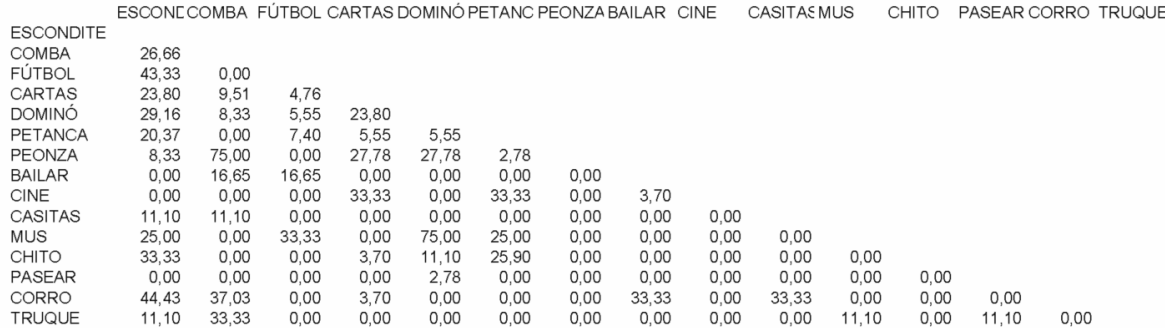

Tabla 13. Distancias para ancianos 